\title{
NOTAS A DOM CASMURRO (EM HOMENAGEM ÀS EDIÇÕES PREPARADAS POR MARTA DE SENNA)
}

\section{LÚCIA GRANJA}

Universidade Estadual de Campinas

Campinas, São Paulo, Brasil

Resumo: Este artigo parte de uma homenagem à Marta de Senna como editora da obra de Machado de Assis, atividade na qual se destaca a obstinação e generosidade que levaram essa estudiosa e editora da obra de Machado de Assis à reunião e edição eletrônica da ficção completa do escritor. Tal reunião e estabelecimento de texto da obra completa do escritor havia sido ensaiada várias vezes, mas jamais cumprida. A seguir, partindo de algumas notas da edição de Senna a Dom Casmurro, o artigo propõe uma análise do ressentimento de Bentinho, baseado na mobilidade da personagem pela cidade do Rio de Janeiro.

Palavras-chave: Machado de Assis; Marta de Senna; edição; ficção completa de Machado de Assis; Dom Casmurro.

\section{REFLEXIONS ON DOM CASMURRO IN HONOR OF THE EDITIONS PREPARED BY MARTA DE SENNA}

Abstract: This article is part of a tribute to Marta de Senna and her work as an editor of Machado de Assis's work, proof of the tenacity and generosity that led this scholar and editor of Machado de Assis's work to publish his complete fiction in an electronic publication. Establishing the texts and notes of Machado's complete works had been attempted several times, but never actually achieved. This article is based on some of de Senna's editor's notes on Dom Casmurro, and offers an analysis of Bentinho's resentment dependent on the character's movements through the city of Rio de Janeiro.

Keywords: Machado de Assis; Marta de Senna; publishing; Machado de Assis's complete fiction; Dom Casmurro. 


\section{Panorama de uma crise quase perene}

$\mathrm{D}$ izer que a genialidade e originalidade de Machado de Assis não receberam, cento e oitenta anos depois de seu nascimento, o acolhimento internacional que a obra desse escritor certamente mereceria ter deflagrado já é quase um lugar-comum. Essa constatação, uma constante lamuriosa da comunidade de leitores do "bruxo do Cosme Velho", funciona como deflagradora para um texto sobre "editar Machado de Assis".

Infelizmente, a obra completa e bem editada do escritor inexiste, como se vê por meio de alguns exemplos que se seguem. Faltavam contos, crônicas e rigor à tentativa da Jackson Inc., em 1935, editora que recebeu os direitos autorais sobre a obra machadiana de Ferdinand Briguiet (HALLEWELL, 2005, p. 268), que, em 1934, tinha se associado a AugustePierre Garnier, sucessor de François-Hippolyte Garnier. A esses dois últimos, desde 1898 até o ano de sua morte, Machado de Assis foi vendendo, sob forma de "propriedade inteira e perfeita", a maioria de suas obras, transferindo assim aos editores "todo o direito de ação, domínio e posse"1 que tinha sobre esses seus escritos.

Já a obra completa da editora José Aguilar, em 1959, com organização de Afrânio Coutinho, priorizou as obras publicadas em livro pelo próprio autor em vida, o que produziu uma lacuna imensa no que se refere aos contos e às crônicas, ali presentes, mas de forma incompleta, sobretudo considerando os contos que restaram nas páginas dos jornais.

Mais tarde, no centenário da morte de Machado, a Nova Aguilar lançou-se à publicação de uma obra completa do escritor, acrescentando a ela textos que haviam ficado de fora da primeira empreitada: poemas, peças de teatro, contos, três séries de crônicas, pequenos textos críticos, textos de polêmicas nas quais se envolveu o jovem Machado etc. Embora bem realizada pelo trabalho de Aluizio Leite, Ana Lima Cecilio e Heloisa Jahn, a obra completa ainda não seria verdadeiramente completa. Segundo os organizadores, essa edição fez crescer "a lista de contos, crônicas, peças de teatro e poesias comprovadamente de sua autoria. A edição de 1959 tinha

\footnotetext{
1 "Escritura de vendas de propriedade literárias que fez Joaquim Maria Machado de Assis a FrançoisHippolyte Garnier, em 16 de janeiro de 1899”, Catálogo da Exposição Machado de Assis: centenário do nascimento de Machado de Assis, p. 186.
} 
3600 páginas. Esta nova, com um volume a mais, quase 6000" (ASSIS, 2008a, v. 1, p. I).

Faltava a correspondência, que começava a ser publicada por outra iniciativa editorial e com a qual hoje em dia contamos em versão completa, ${ }^{2}$ além de alguns textos críticos. Para analisar a dificuldade da tarefa, é interessante verificar a forma pela qual isso aparece justificado na "Nota editorial" desse trabalho, sem dúvida, de fôlego: "[...] é fundamental deixar claro que esta nova edição da obra completa de Machado de Assis é destinada ao grande público, e, portanto, nunca pretendeu ter o caráter de edição crítica" (ASSIS, 2008a, v. 1, p. I). Em não se apresentando como uma edição crítica, a Obra Completa em quatro volumes aplaca as críticas: um ou outro texto que falte, entre os gêneros privilegiados (poemas, teatro, contos, romances, crítica e crônicas) não a compromete. Na mesma nota editorial, declara-se que a questão da atribuição certeira de autoria de textos a Machado de Assis é critério importante para vários deles que não foram incorporados à coleção, o que resolve o problema de consagrar textos como sendo machadianos e, por infortúnio, descobrir-se um dia que não o são, o que fez a Jackson com algumas crônicas, por exemplo. A explicação dá conta também do dilema contrário: em se descobrindo mais algum texto machadiano, como efetivamente aconteceu pela via das pesquisas que se multiplicaram graças à Hemeroteca Digital da Biblioteca Nacional, ${ }^{3}$ a coleção da Aguilar está mais ou menos isenta de responsabilidade porque "catar o mínimo e o escondido", ${ }^{4}$ nas páginas dos periódicos, por exemplo, não era seu objetivo.

Houve várias outras tentativas de completar esse quadro geral da obra machadiana. A respeito das crônicas, depois de terem sido apresentadas em várias edições sem preocupação com a sua completude e sem paratextos de contextualização (em um gênero que em muito depende de sua vinculação direta com os fatos), apareceu, na Unicamp, em 2003, um projeto que propunha a coleção completa das crônicas de Machado de Assis, em mais de uma dezena de volumes, edições com estabelecimento de textos a partir de pesquisa nos próprios periódicos, notas para contextualização, notas de texto

\footnotetext{
${ }^{2}$ Refiro-me à Correspondência de Machado de Assis, 5 tomos, sob coordenação e orientação de Sergio Paulo Rouanet, reunida, comentada e organizada por Irene Moutinho e Silvia Eleutério, publicada pela ABL entre 2008-2015.

${ }^{3}$ Wilton Marques (2016) localizou um poema ("O grito do Ipiranga", Correio Mercantil, 1856) e um projeto de livro (Livro dos vinte anos, que seria publicado por Paula Brito) em suas pesquisas na Hemeroteca Digital Brasileira (vide referências bibliográficas).

${ }^{4}$ A expressão é de Machado de Assis em uma derradeira crônica escrita para "A Semana”, Gazeta de Notícias, em 11 de novembro de 1897.
} 
e introduções críticas sólidas, à moda do que John Gledson vinha ensinando ao Brasil sobre o texto machadiano, sendo, Gledson, aliás um dos diretores da coleção, posição que dividia com Sidney Chalhoub. O projeto deveria culminar nas homenagens a Machado de Assis no centenário de sua morte, mas 2008 viu aparecerem três séries apenas: a reedição de Bons Dias!, que John Gledson publicara pela Hucitec em coedição com a editora da Unicamp, em 1986; os Comentários d"“A Semana”, preparados por Jefferson Cano e Lúcia Granja (ASSIS, 2008c), bem como as Notas Semanais, nas quais trabalharam John Gledson e Lúcia Granja (ASSIS, 2009d). Um pouco depois, vieram $O$ Espelho, volume organizado por João Roberto Faria (ASSIS, 2009a), Histórias de quinze dias, por Leonardo A. M. Pereira (ASSIS, 2009b) e, com o tempo, O Futuro (ASSIS, 2014), em cuja edição trabalhou Rodrigo C. de Godói. Infelizmente, o espaçamento entre esses últimos volumes significa o que está indicado: dificilmente os outros oito volumes previstos aparecerão um dia, ou seja, nessa empreitada, a edição anotada e com estabelecimento de texto das crônicas completas de Machado de Assis restará incompleta. O que houve com a equipe da Unicamp, entre 2003 e 2008, aconteceu a outros grupos que tentaram reunir completamente e editar criticamente a obra de Machado de Assis, ou parte dela: divergências e/ou dissidências (Cf. SILVA; FARIA; MARQUES; GRANJA, 2009).

Nesse particular de insucesso, a coleção incompleta, guardadas as devidas proporções, invoca a importante "Comissão Machado de Assis", que, instituída durante o governo Juscelino Kubitschek (portaria $\mathrm{n}^{\circ} 483$, datada de 19 de setembro de 1958, do Ministério da Educação e Cultura), após o mesmo órgão ter declarado a obra de Machado de Assis como de domínio público, por despacho de 15 de setembro de $1958,{ }^{5}$ trabalhou com competência ímpar na edição crítica de contos e romances, mas não pôde concluir a coleção completa da ficção machadiana, tendo deixado de fora dos trabalhos Papéis avulsos e as Páginas recolhidas. Nos dias de hoje, nesse espaço deixado pela coleção abortada das crônicas completas, outras iniciativas individuais e complementares têm aparecido, publicadas por editoras e mesmo em suportes diversificados. ${ }^{6}$ É bom para a obra

\footnotetext{
${ }^{5}$ Devo essa última informação ao artigo de Alex Sander Luiz Campos, "Edições de Machado de Assis: por quê, para quê?" (CAMPOS, 2008).

${ }^{6}$ Silvia Maria Azevedo lançou-se a essa tarefa hercúlea. Publicou, em 2011, pela editora da Unesp, uma edição anotada da série História dos quinze dias, Histórias dos trinta dias; em seguida, compilou todos os textos machadianos sobre crítica literária em Machado de Assis: crítica literária e textos diversos (2013), quer fossem específicos sobre isso, quer tenha extraído as referências dos textos das crônicas, o que, aliás, também fizera João Roberto Faria com os textos sobre teatro (Machado de Assis: do teatro, 2008). Recentemente, Azevedo fez uma edição completa da série "Badaladas" (Badaladas - Dr.
} 
machadiana, que aparece cada vez mais em boas edições; é ruim para a obra machadiana porque, para lê-la por completo, já é preciso ser um especialista em suas incompletudes e descontinuidades.

\section{Suportes diversos}

Uma das tentativas isoladas de se completar as edições das crônicas de Machado de Assis vem da revista Machadiana Eletrônica, que acolhe, neste momento, a edição restante da série "A Semana” (1892-1897), ${ }^{7}$ preparada pelo trabalho apaixonado de John Gledson. Essa ação meritória invoca diretamente o site pioneiro que Marta de Senna desenvolveu ao longo de sua passagem como pesquisadora e dirigente de uma das instituições de pesquisa mais renomadas do país, a Fundação Casa de Rui Barbosa, a qual define sua missão como "o desenvolvimento da cultura, da pesquisa e do ensino, a divulgação e o culto da obra e vida de Rui Barbosa. (Lei 4.693, de 06-041966)". 8 Sem exagero algum, depois de Marta de Senna, no imaginário da comunidade machadiana, a Casa Rui passou a ser também o lugar do "culto da obra de Machado de Assis". Ali foram gestados, vieram à luz, cresceram e se multiplicaram a revista acadêmica Machado de Assis em Linha - hoje em dia sob a responsabilidade de dois parceiros constantes de Marta de Senna, Hélio de Seixas Guimarães, na Universidade de São Paulo, além de Marcelo Diego, na Universidade Federal do Rio de Janeiro. A pesquisadora criou também o sítio eletrônico "machadodeassis.net", que abriga a base de dados de "Citações e alusões nos romances e contos de Machado de Assis", bem como os "Romances e contos em hipertexto", projetos que acompanharam a maior parte da trajetória de Marta de Senna pela Casa Rui.

Sendo esses os resultados finais, Marta de Senna intuiu, antes de 1998, ou antes de conhecermos os "modos de usar" da rede mundial de computadores, que o estudo das referências e alusões do texto machadiano

\footnotetext{
Semana, 2019), procurando resolver os problemas de identificação de autoria. Na mesma linha de busca por boas edições isoladas das crônicas machadianas, a revista Machadiana Eletrônica, editada por José Américo Miranda, tem acolhido a edição restante da série "A Semana" (1892-1897), que John Gledson começou a publicar em livro (Hucitec, 1996), tendo coberto o período de 1892-1893. Por enquanto, a mencionada revista publicou, com edição e notas de John Gledson, o ano de 1894 da série "A Semana".

${ }^{7}$ Conferir mais detalhes na nota 6 deste texto.

8 "Missão". Disponível em: <http://www.casaruibarbosa.gov.br/interna.php?ID_S=10>. Acesso em: 15 ago. 2019.
} 
era de fundamental importância para conhecer a ficção do autor. Cito $O$ olhar oblíquo do bruxo:

[de Machado] se irradiam considerações sobre os [autores] estrangeiros e sobre o diálogo intertextual que se estabelece entre eles e o autor brasileiro. O ponto de chegada é também Machado, porque foi só para entendê-lo melhor que fui entender os outros (SENNA, 1998, p. 9-10).

Ou, ainda, em Alusão e zombaria: considerações sobre citações e referências na ficção de Machado de Assis:

As relações intertextuais entre os romances de Machado de Assis e a produção literária ocidental são uma indicação segura de que era um leitor voraz. Não há, praticamente, narrativa machadiana que não cite outros autores, não aluda a outras obras, que não se reporte a outros escritos, num universo temático, cronológico e geográfico de magnitude e sem precedentes (e sem sucessores) na literatura brasileira (SENNA, 2003, p. II).

O universo das leituras machadianas reconstitui-se no trabalho de Marta de Senna como via de mão dupla, que vai de sua ficção à dos pares e vem deles a Machado, que os chama constantemente para seus textos. Especial em relação à perspectiva comparatista ou à metodologia da intertextualidade, são a frequência com que Machado o fez, produzindo, pelas citações e alusões, uma rede de tecidos interpretativos que costura sob a malha de seu texto. Subliminar àqueles estudos dos textos machadianos, estava a percepção que só uma nova forma de edição recuperaria as sutilezas das práticas de leitura da época, afinal o uso machadiano da citação e alusão literárias é hiper-relacional. Nosso escritor movia seu texto, constantemente, de um suporte midiático (os periódicos) ao individualista e silencioso livro. Nos periódicos, a constante referência dos textos machadianos a outros e variados textos (literários ou publicados em outros periódicos da época) adotava a prática hipertextual mnemônica, que está na origem da atual forma hipertextual eletrônica, portanto (GRANJA, 2018).

A edição completa e definitiva da ficção de Machado de Assis aconteceu finalmente, seguindo a prática do mestre Machado, depois de uma transposição de suporte: do papel à tela. Ela materializou-se na aba "Romances e contos em hipertexto" de www.machadodeassis.net, para cada conto e para cada romance conhecido de Machado de Assis, na forma: do estabelecimento criterioso de texto, a partir das melhores edições existentes 
(isoladas ou obra quase completa), e de critérios de atualização gramatical, com destaque para ortografia e pontuação, tudo assentado sobre uma base de erudição sólida; do fazer de cada edição um instrumento de pesquisa que possibilita aos leitores atuais o mesmo conjunto de referências que Machado de Assis exigia de seus leitores contemporâneos, ou a possibilidade de localizar autores citados, obras mencionadas, fatos históricos, personagens (ficcionais ou históricas), lugares (desde que tenham conotação alusiva ou simbólica) nomeados ou a que se faz alusão, fontes anônimas como provérbios, ditados e adágios, além de criações coletivas, como a Bíblia, a Mitologia Clássica, ou a História.

A obra de ficção de Machado de Assis está, enfim, bem editada, anotada, completa e a um lance de dedos do leitor. Era isso, afinal, o que a obra de Machado de Assis pedia de seus estudiosos?

\section{Dom Casmurro: notas depois das notas}

A intertextualidade foi largamente estudada pela crítica machadiana. Nesse panorama, os sentidos mobilizados pelo conjunto de referências presentes na obra de Machado de Assis vão muito além da citação ou alusão a autores e textos impressos. Alguns caminhos percorridos pela crítica têm sido os fatos históricos e os lugares, notadamente a cidade do Rio de Janeiro. Cabe, então, demonstrar como a insistência com que o site www.machadodeassis.net coloca à disposição do pesquisador as mais variadas informações e oferece, generosamente, novas possibilidades de leitura aos textos machadianos.

Em destaque, o Rio de Machado de Assis. Sem distinção, os personagens e enredos machadianos passeiam pelo Centro, Catumbi, Glória, Laranjeiras, Botafogo, Rio Comprido, Santa Teresa, Tijuca, Catete, Zona Portuária, Andaraí, Copacabana, Flamengo e Engenho Novo, sem esgotar a enumeração de bairros.

Uma personagem se destaca entre várias porque, já no segundo capítulo de seu romance memorialista, põe em foco um "desejo tão particular", e realizado, de "reproduzir no Engenho Novo a casa em que me criei na antiga rua de Matacavalos, dando-lhe o mesmo aspecto e economia 
daquela outra, que desapareceu". 9 A trajetória de Bentinho-Casmurro pelo Rio de Janeiro parte, portanto, da rua de Matacavalos, que a nota de localização elaborada em www.machadodeassis.net explica ser a:

[...] atual Riachuelo, [que] situa-se no centro do Rio de Janeiro. O nome "Matacavalos" adviria da existência de atoleiros que dificultavam a passagem e cansavam os animais, que, às vezes, caíam e acabavam por ter de ser sacrificados. Outra explicação para a origem do nome são as árvores chamadas "mata-cavalos", que existiam ao longo do caminho. A rua passou a chamar-se "do Riachuelo" em 1865, em homenagem à batalha naval desse nome, ocorrida durante a Guerra do Paraguai. No decorrer do século XIX, era uma rua onde moravam pessoas da elite econômico-social da Corte do Rio de Janeiro. ${ }^{10}$

Apesar do nome e da origem possivelmente ligados à alimária e a caminhos difíceis, Bentinho parte de uma região que, na cidade do Rio de Janeiro de meados do século XIX (ele tinha 15 anos em 1857), abrigava a elite econômica, o que contribuía para reforçar o preconceito social em relação aos "vizinhos pobres, meio dependentes de D. Glória, enquanto Bentinho pertence a uma família de classe dominante, cujo chefe havia sido fazendeiro e deputado, e deixava bastante propriedade" (SCHWARZ, 1997, p. 14). Nesse particular, aliás, o narrador casmurro declara, no capítulo VII, "Dona Glória”, que sua mãe:

[...] era boa criatura. Quando lhe morreu o marido, Pedro de Albuquerque Santiago, contava trinta e um anos de idade, e podia voltar para Itaguaí. Não quis; preferiu ficar perto da igreja em que meu pai fora sepultado. Vendeu a fazendola e os escravos, comprou alguns que pôs ao ganho ou alugou, uma dúzia de prédios, certo número de apólices, e deixou-se estar na casa de Matacavalos, onde vivera os dous últimos anos de casada. Era filha de uma senhora mineira, descendente de outra paulista, a família Fernandes. ${ }^{11}$

\footnotetext{
${ }^{9} \mathrm{~A}$ partir de agora, todas as referências a Dom Casmurro são tomadas à edição eletrônica com notas em hipertexto preparada por Marta de Senna. Disponível em: <http://www.machadodeassis.net/hiperTx_romances/obras/domcasmurro.htm>. Acesso em: 15 ago. 2019. 10 Disponível em: <http://www.machadodeassis.net/hiperTx_romances/obras/domcasmurro.htm>. Acesso em: 15 ago. 2019.

11 Disponível em: <http://www.machadodeassis.net/hiperTx_romances/obras/domcasmurro.htm>. Acesso em: 15 ago. 2019.
} 
A filha da família tradicional brasileira, como o narrador faz questão de destacar, herdou do marido uma "fazendola", cuja venda rendeu à boa senhora apólices, uma dúzia de prédios no Rio de Janeiro, além de escravos de ganho, entre outras propriedades. Dona Glória era, então, suficientemente rica para que também se tornasse rico o seu único herdeiro. Ademais, era uma senhora de hábitos reclusos e modestos, o que indica não ter desperdiçado grandes somas. Mais tarde, Bentinho, progredindo à época de seu casamento com Capitu - o que não teria feito sem um bom "empurrão" de Escobar, como se vê a seguir -, muda-se para uma região ainda mais agradável da cidade, a praia da Glória, que acolheu a "aristocracia carioca até meados do século XX", segundo a informação que traz o aplicativo "Rio de Machado", ${ }^{12}$ um outro produto inspirado na transmidialidade pioneira de www.machadodeassis.net. Segundo o narrador, Capitu estava muito consciente desses seus novos estados, civil e financeiro. É o que mostra no capítulo CII, "De casada":

A alegria com que pôs o seu chapéu de casada, e o ar de casada com que me deu a mão para entrar e sair do carro, e o braço para andar na rua, tudo me mostrou que a causa da impaciência de Capitu eram os sinais exteriores do novo estado. [...] $\mathrm{Na}$ rua, muitos voltavam a cabeça curiosos, outros paravam, alguns perguntavam: “Quem são?” E um sabido explicava: "Este é o doutor Santiago, que casou há dias com aquela moça, D. Capitolina, depois de uma longa paixão de crianças; moram na Glória, as famílias residem em Matacavalos." E ambos os dous: "É uma mocetona!". ${ }^{13}$

Já casado, os negócios iam bem e a fortuna de Bento deveria continuar a crescer. À mesma época, estreitavam-se as relações entre o casal da praia da Glória e o do Andaraí, como nomeia Bentinho, no capítulo CIV, "As pirâmides":

[...] Tudo corria bem. Ao fim de dous anos de casado, salvo o desgosto grande de não ter um filho, tudo corria bem. [...]

Eu era advogado de algumas casas ricas, e os processos vinham chegando. Escobar contribuíra muito para as minhas estreias no foro.

\footnotetext{
${ }^{12}$ A informação está, por exemplo, no aplicativo "Rio de Machado", quando se descreve as regiões da cidade do Rio de Janeiro mencionadas em Dom Casmurro.

13 Disponível em: <http://www.machadodeassis.net/hiperTx_romances/obras/domcasmurro.htm>. Acesso em: 15 ago. 2019.
} 
Interveio com um advogado célebre para que me admitisse à sua banca, e arranjou-me algumas procurações, tudo espontaneamente.

Demais, as nossas relações de família estavam previamente feitas; Sancha e Capitu continuavam depois de casadas a amizade da escola, Escobar e eu, a do seminário. Eles moravam em Andaraí, aonde queriam que fôssemos muitas vezes, e, não podendo ser tantas como desejávamos, íamos lá jantar alguns domingos, ou eles vinham fazê-lo conosco. Jantar é pouco. Íamos sempre muito cedo, logo depois do almoço, para gozarmos o dia compridamente, e só nos separávamos às nove, dez e onze horas, quando não podia ser mais. Agora que penso naqueles dias de Andaraí e da Glória, sinto que a vida e o resto não sejam tão rijos como as Pirâmides. [...]

Quando não estávamos com a família ou com amigos, ou se não íamos a algum espetáculo ou serão particular (e estes eram raros) passávamos as noites à nossa janela da Glória, mirando o mar e o céu, a sombra das montanhas e dos navios, ou a gente que passava na praia.

No trecho acima, o Casmurro destaca a bela vista que se abria das janelas frontais de sua casa, das quais vislumbrava a praia, o céu e os passantes. Existe nessa lembrança uma ponta de vaidade, posto que o avistar pela janela é apenas um dos vetores do movimento completo: ser visto à janela. Aliás, era esse mesmo ciumento que inspirava em Capitu o hábito de evitá-las. Evocando a memória e lembrando-se dos amigos passados, é importante observar que os dias de felicidade eram aqueles nos quais estava Bentinho na praia da Glória e Escobar no Andaraí. Ainda pensando naqueles mesmos dias de Andaraí e da Glória, o Casmurro constata que a vida e "o resto" não eram rijos como as pirâmides. Mas o que seria "o resto"? Esgotarse-ia essa referência na infelicidade conjugal vindoura? Desse mesmo capítulo CIV não está longe o CXVII, "Amigos próximos”:

Já então Escobar deixara Andaraí e comprara uma casa no Flamengo, casa que ainda ali vi, há dias, quando me deu na gana experimentar se as sensações antigas estavam mortas ou dormiam só; não posso dizê-lo bem, porque os sonos, quando são pesados, confundem vivos e defuntos, a não ser a respiração. Eu respirava um pouco, mas pode ser que fosse do mar, meio agitado. Enfim, passei, acendi um charuto, e dei por mim no Catete; tinha subido pela rua da Princesa, uma rua antiga...ó ruas antigas! Ó casas antigas! Ó pernas antigas! Todos nós éramos antigos, e não é preciso dizer que no mau sentido, no sentido de velho e acabado. 
O mal-estar, ou a constatação da ruína (ruas, casas e pessoas estavam velhas e/ou acabadas), vem evocado justamente pela decisão de passar diante da casa que Escobar comprara no Flamengo, ali perto da praia da Glória. Escobar e Sancha viveram, afinal, poucos anos, na boa chácara do Andaraí, que, como lembra a nota de "lugar" oferecida pelo trabalho de edição e anotação de Marta de Senna, é, hoje em dia, um bairro de classe média, na zona Norte, sendo, ainda, um dos bairros mais antigos da cidade. Curiosamente, foi nesse momento de maior proximidade física entre as residências dos dois casais que os problemas de Bentinho começaram a crescer. Os ciúmes, mistos de um mal-estar que as memórias do Casmurro traduzem com assombrosa eficácia, cresceram exponencialmente. No trecho acima, sobre a proximidade física dos dois casais, ele insinua com o singelo ditado "longe dos olhos, longe do coração", que se opunha à ilustração que João de Barros deu à proximidade de dois amigos, sendo ditado popular e referência histórica localizados e esclarecidos pelas anotações da edição de Marta de Senna.

O Casmurro explica que o escritor e historiador renascentista atribui a um rei amigo dos portugueses, em cujos domínios os nossos patrícios estabeleceram uma fortaleza, a seguinte reflexão: “[...] dizia o rei que os bons amigos deviam ficar longe uns dos outros, não perto, para se não zangarem como as águas do mar que batiam furiosas no rochedo que eles viam dali". ${ }^{14}$ Ao pé da letra, são as águas do mar que inspiram a fúria dos vizinhos. Se as esposas se frequentavam e os filhos dos casais brincavam juntos, foi a partir desse ponto que Bentinho passa a sentir com fúria crescente os ciúmes de Escobar e as desconfianças de Capitu; ao mesmo tempo, confusamente em meio a esse mal-estar, deixa crescer e fluir o seu desejo por Sancha (e quem sabe por "um quatuor", o que quer que isso signifique nesse contexto). É preciso lembrar que imediatamente após o capítulo em que relembra a mudança do casal amigo ao Flamengo, Bentinho deseja a mulher do amigo (capítulo CXVIII, “A mão de Sancha”), o que se percebe por meio de um encontro forçado e talvez imaginado de olhos, além de um aperto demasiado longo de mãos. Ao mesmo tempo, dá-se o já bastante referido lance em que

\footnotetext{
${ }^{14}$ Sobre essa referência a João de Barros, Marta de Senna, em nota, esclarece que "João de Barros (1496-1590), historiador e escritor do Renascimento, foi apelidado o Tito Lívio português. Suas obras mais famosas são a Gramática da língua portuguesa e as Décadas da Ásia. O episódio a que se refere o narrador está na Década primeira (III, 2): o príncipe africano Caramansa, da Guiné, assim responde ao português Diogo de Azambuja (1432-1518), explorador da costa africana sob D. João II e D. Manuel. Os portugueses ali queriam construir (e de fato o fizeram) o forte de São Jorge de Mina, primeiro entreposto comercial construído no golfo da Guiné, em 1482, na costa do que hoje é o país Gana."
} 
toca com admiração, e sentindo "outra coisa", os braços forte e grossos de "seu amigo e comborço". ${ }^{15}$

Nesse contexto, a fantasia erótica envolvendo a mulher de outro homem, ou mesmo um quatuor, podem ser considerados meios de acesso ao corpo desejado de Escobar. Tudo isso, na sequência da memória reconstruída, sucede-se à melhora de situação social da família Escobar e consequente deslocamento pelos bairros do Rio de Janeiro. O Andaraí era certamente um bom bairro residencial, embora mais afastado, longe da brisa do mar e dos passantes. Enquanto isso, o Flamengo, como nos explica a nota em hipertexto elaborada por Marta de Senna e sua equipe, “[...] é um bairro litorâneo da zona Sul do Rio de Janeiro [...]. No século XIX o Flamengo se converteu em um bairro residencial de alta categoria". ${ }^{16}$

Anos depois, seria no Engenho Novo, não longe do Andaraí, que o Casmurro arquitetaria toda essa narrativa, depois que se lembrou de "reproduzir [...] a casa em que me criei na antiga rua de Matacavalos, dandolhe o mesmo aspecto e economia daquela outra, que desapareceu". A primeira nota de texto do romance no site machadodeassis.net aprofunda a notícia sobre o Engenho Novo:

O Engenho Novo é um bairro do Rio de Janeiro, localizado na zona Norte da cidade. A região foi inicialmente ocupada pelos jesuítas, que nela instalaram três engenhos: o Engenho Velho, o de São Cristóvão e o Engenho Novo. Neste último, construíram uma capela dedicada a São Miguel e a Nossa Senhora da Conceição. No século XIX, foi aberta a estrada de ferro D. Pedro II (Central do Brasil), que passa pela estação do Engenho Novo. ${ }^{17}$

O Engenho Novo onde reside Bento Santiago maduro e casmurro era, portanto, à época presumida do enredo, próxima à da escritura do romance,

\footnotetext{
${ }^{15}$ Marcelo Diego, no instigante artigo "Meu amigo e comborço: dimensões homoeróticas do Dom Casmurro de Machado de Assis", analisa as relações homoeróticas em Dom Casmurro, entre outros, por meio da investigação do "ciúme" à luz da psicanálise. Destaco aqui a ênfase dada pelo autor do artigo nas relações entre ciúmes e homoerotismo, segundo a definição que Freud dá a esse sentimento e a duas entre as três classificações que o mestre da Psicanálise dá aos ciúmes, o projetado e o delirante. Fica claro que, no projetado, os ciúmes projetam no parceiro as próprias culpas, como se os ciúmes que Bento sentia de Capitu expiassem o ilegítimo de seus próprios desejos extraconjugais; já no delirante, o motivo das fantasias de Bento seria o desejo homossexual reprimido, Escobar.

16 Disponível em: <http://www.machadodeassis.net/hiperTx_romances/obras/domcasmurro.htm>. Acesso em: 15 ago. 2019.

17 Disponível em: <http://www.machadodeassis.net/hiperTx_romances/obras/domcasmurro.htm>. Acesso em: 15 ago. 2019.
} 
um bairro do Rio de Janeiro que se desenvolveu depois de meados do século, no qual se inaugurou a estação de trem em 1858, arrastando para a localidade uma maior quantidade de população. Ele estava à época (e ainda hoje) situado fora das regiões mais valorizadas da cidade. Os dois amigos descrevem, portanto, trajetórias opostas no romance. Filho de uma família de recursos medianos, Escobar conquista a beira-mar; filho de uma família abastada, Bentinho, não sabe o porquê de ser empurrado para um bairro mais longínquo e menos bem situado. A máscara da casmurrice ajuda a apagar as perdas financeiras, embora o Casmurro ainda vivesse bem. Bentinho movimenta-se no eixo centro-praia da Glória-norte da cidade do Rio de Janeiro e, nessa derradeira ponta da vida, destila sua amargura em palavras. Escobar, menos rico de partida, filho de um advogado de Curitiba, tinha no Rio de Janeiro poucas referências, mas conquista, com inteligência, agudeza e trabalho, o bairro do Flamengo, onde é, afinal, tragado pelas águas do mar furioso. ${ }^{18}$

Filho de uma senhora viúva que, à sua época, foi rica e viveu como rentista, seria exagerado concluir, após esse passeio pelo Rio de Janeiro, que a argúcia e mérito de Escobar são alvo, entre outros, do ressentimento de classe de Bentinho? Quais foram realmente as grandes perdas financeiras e de capital sofridas por ele? Os escravos de ganho que se foram com o tempo e com a Abolição? A dúzia de prédios consumida pelo advogado pouco produtivo (que conquistara, no início, um bom emprego e clientes graças a Escobar)? O que foi feito das apólices? Bentinho seria mais uma vítima da política do Encilhamento, do desânimo após a separação?

Fundamental identificar e poder analisar os lugares machadianos. Deslocando-se pelo Rio de Janeiro, as personagens de Machado de Assis contam, pelas ruas e bairros da cidade, minúcias de sua fabulação ficcional e das histórias de um tempo que passou. Em Dom Casmurro está o rançoso ressentimento das classes brasileiras que sentem perder quando o outro ganha ou se aproxima. Mal ganhou o Flamengo, Escobar anuviou os sentimentos e percepções de Bentinho, quer seja por medo, desejo ou inveja. Ao fim e ao cabo, fica uma constatação que desafia ainda hoje a sociedade brasileira: contrariamente ao que diz o narrador melancólico, aquelas ruas, casas e pernas antigas do Flamengo ainda não se tornaram velhas: o que dizer dos ressentimentos...

\footnotetext{
${ }^{18} \mathrm{O}$ ressentido Casmurro faz questão de destacar, por ocasião do velório de Escobar, que a casa onde residia a família do amigo e comborço não era grande.
} 


\section{Referências}

ASSIS, Machado de. A Semana. Crônicas (1892-1893). Edição, introdução e notas de John Gledson. São Paulo: Editora Hucitec, 1986.

. Obra completa em quatro volumes. $2^{\mathrm{a}}$. ed. Organização de Aluizio Leite, Ana Lima Cecilio, Heloísa Jahn. Rio de Janeiro: Aguilar, 2008a.

Machado de Assis: do teatro. Organização de João Roberto Faria. São Paulo: Perspectiva, 2008b.

. Comentários da Semana. Org., introdução e notas de Lúcia Granja e Jefferson Cano. Campinas, SP: Editora da Unicamp, 2008c.

Notas Semanais. Org., introdução e notas de John Gledson e Lúcia Granja. Campinas, SP: Editora da Unicamp, 2008d.

- Correspondência de Machado de Assis. Coordenação e orientação de Sergio Paulo Rouanet, reunida, comentada e organizada por Irene Moutinho e Silvia Eleutério. 5 tomos. Rio de Janeiro: ABL, 2008-2015.

O Espelho. Org., introdução e notas de João Roberto Faria. Campinas; SP: Editora da Unicamp, 2009a.

História de quinze dias. Org., introdução e notas de Leonardo Affonso de Miranda Pereira. Campinas; SP: Editora da Unicamp, 2009b.

. História de quinze dias, Histórias de trinta dias. Crônicas de Machado de Assis - Manassés. Organização de Silvia Azevedo. São Paulo: Editora da Unesp, 2011.

Machado de Assis: crítica literária e textos diversos. Org. de Silvia Azevedo, Adriana Dusilek e Daniela Mantarro Calipo. São Paulo: Editora da Unesp, 2013.

. O Futuro. Org., introdução e notas de Rodrigo Camargo de Godói. Campinas; SP: Editora da Unicamp, 2014.

. O grito do Ipiranga. Poema inédito localizado por Wilton José Marques. Disponível

em:

<http://www.saci.ufscar.br/data/clipping/imagens/32932_00.jpg>. Acesso em: 03 set. 2019.

Badaladas - Dr. Semana. Org. de Silvia Maria Azevedo. 2 v. São Paulo: Nankin Editorial, 2019.

CAMPOS, Alex Sander Luiz. Edições de Machado de Assis: por quê, para quê?. Machadiana Eletrônica, Vitória, v. 1, n. 1, jan-jul 2018, p 131-150.

CATÁLOGO DA EXPOSIÇÃO MACHADO DE ASSIS: centenário do nascimento de Machado de Assis, 1839-1939. Rio de Janeiro: Serviço gráfico do Ministério da Educação, 1939.

DIEGO, Marcelo. Meu amigo e comborço. Dimensões homoeróticas do Dom Casmurro de Machado de Assis. Luso-Brazilian Review, Wisconsin University Press, v. 54, n. 1, 2017, p. 138-158. 
GRANJA, Lúcia. Machado de Assis, antes do livro, o jornal: suporte, mídia e ficção. São Paulo: Editora da Unesp, 2018.

HALLEWELL, Laurence. O livro no Brasil: sua história. $2^{\text {a }}$ edição revista e ampliada. São Paulo: Editora da Universidade de São Paulo, 2005.

MARQUES, Wilton José. As primeiras incertezas, o profeta machadiano e o malogro do primeiro livro. Machado de Assis em Linha, São Paulo, v. 9, n. 19, dez. 2016, p. 11-33.

SENNA, Marta de. O olhar oblíquo do bruxo: ensaios em torno de Machado de Assis. Rio de Janeiro: Nova Fronteira, 1998.

Alusão e zombaria: considerações sobre citações e referências na ficção de Machado de Assis. Rio de Janeiro: Fundação Casa de Rui Barbosa, 2003.

SCHWARZ, Roberto. A poesia envenenada de Dom Casmurro. In: Duas meninas. São Paulo: Companhia das Letras, 1997.

SILVA, Ana Claudia Suriani da Silva; FARIA, João Roberto; MARQUES, Ivan; GRANJA, Lúcia. Edições e reedições do centenário. Machado de Assis em Linha, n. 4, dez. 2009, p. 33-66.

Sites:

Missão descrita no site da Fundação Casa de Rui Barbosa. Disponível em:

<http://www.casaruibarbosa.gov.br/interna.php?ID_S=10>. Acesso em: 15 ago. 2019.

$<\mathrm{http}: / /$ www.machadodeassis.net $>$. Consulta em diversas datas.

Dom Casmurro. Disponível

em:<http://machadodeassis.net/hiperTx_romances/obras/domcasmurro.htm>.

Consulta em diversas datas.

LÚCIA GRANJA é professora de Literatura e Cultura Brasileiras na Unicamp, Livre-Docente em Literatura Brasileira pela Unesp (2016), Doutora em Teoria e História Literária pela Unicamp (1997). Pesquisadora da obra de Machado de Assis, especializou-se no estudo das crônicas do escritor e das relações entre Literatura e Jornalismo em sua obra. Estuda também a História do Livro e da Edição no Brasil e em suas relações com a França, sobretudo a história dos livreiros e editores Garnier. É autora de Machado de Assis, escritor em formação: à roda dos jornais (Editora Mercado das Letras, 2000) e Machado de Assis - antes do livro o jornal: suporte, mídia e ficção (Editora da Unesp, 2018). 